\title{
Application of Audio-Magnetotelluric Method for Exploration the Concealed Ore-Bodies in Yuele Lead-Zinc Ore Feild, Daguan County, NE Yunnan Province, China
}

\author{
Tran Trong Lap1, Chuandong Xue1, Aiying Wei1, Lv Liư1, Wenyao Li1, Qiquan Hu², \\ Jingjie $\mathrm{Li}^{2}$, Dafeng Luo ${ }^{2}$, Shaoyong Zhu², Tiangui Zhang' \\ ${ }^{1}$ Department of Earth Sciences, Kunming University of Science and Technology, Kunming, China \\ ${ }^{2}$ Daguan Chihong Mining Co. Ltd., Yunnan Chihong Zinc and Germanium Co. Ltd., Daguan, China \\ Email: tronglaptran@imgg.vast.vn, cdxue001@aliyun.com
}

Received February 2014

\begin{abstract}
The results of recent mineral exploration in the Yuele lead-zinc mining area of Daguan County, northeastern Yunnan province, showed that there are much early Paleozoic strata under thick late Paleozoic strata in northeastern Yunnan province, where developed some hidden salt structures (SSs), often with lead-zinc polymetallic mineralization varying degrees along the tension torsional fault (belts) or fracture (joint). The ore-bodies belong to the epigenetic hydrothermal filling vein-type deposit, and the prospecting potential is great. In this area, the superficial mineralization information displayed clear, but the deep mineralization is unknown, so the exploration work is restricted. The audio-megnetotelluric (AMT) surveying is an advantageous method to characterize the size, resistivity and skin depth of the polarizable mineral deposit concealed beneath thick overburden. This paper presents the surveying results using AMT method to evaluate the concealed lead-zinc mineralization in Yuele lead-zinc ore field, Daguancounty, NE Yunnan province, China. After comparing the interpretation result of AMT surveying data with the geological data and the drilling data, it is found that there is some distinct difference in resistivity and polarizable between ore-bodies hosted strata, upper strata and gypsum strata. The results show that AMT method is helpful to identify lead-zinc mineralization under this geological condition.
\end{abstract}

\section{Keywords}

Audio-Magnetotelluric Method (AMT), Physical Anomaly, Concealed Ore-Bodies Predicting, Salt Tectonics (SSs), Yuele Lead-Zinc Ore Field, NE Yunnan Province

\section{Introduction}

Due to the complexity of geological conditions and mineralization, it is very difficult to obtain good results for the mineral prospecting researching only through the geological metallogenic laws. Currently, mineral pros- 
pecting methods based solely on geological theory haven't been met the requirements of modern mineral exploration (Wang et al., 2009; Xue et al., 2010, 2012). So that, it is necessary to arrange reasonably the prospecting projects, along with research and application the geophysical methods to predict the location of the concealed ore-bodies.

Along the metallogenic belt in northeastern Yunnan province that is important composition of the lead-zinc polymetallic mineralization area in Sichuan-Yunnan-Guizhou, there has found more than 130 lead-zinc deposits and mining areas with different large and medium scale "Figure 1(A)". But this region exist the minor axis anticline outcrop area with early Paleozoic strata and underlying very thick late Paleozoic strata. And in the tension-torsional faulted and shattered zone or intersection of different direction faults, it developed many lead-zinc polymetallic deposits or mineralizating points with different poor and rich degree. In many areas, the mineralization bodies are relatively obvious on ground shallows, but it is very difficult and not clear for the prospecting potential in the depth, the prospecting progress is slow. It has great prospect for copper-lead-zinc mining prospecting in Yuele lead-zinc ore field. Recently, the projects for prospecting evaluation and mineral geological observation in this area found that the mineralization patterns and geological characteristics of the stratiform and steep dipping vein ore-bodies (Xue et al., 2010, 2012). Because the developing of the folds and faults in this area, geochemical observation has found some mineralization anomalies, but the vein shape ore-bodies have great variations, and the occurring of the salt tectonics in the depth. So the deep concealed ore-bodies prediction and exploration have been limited largely.

This article took the lead-zinc deposit in the Yuele mining area as the object to study the metallogenic prospecting method. To help characterizing the size, electrical resistivity and skin depth of the polarizable mineral deposits concealed beneath thick overburden, so audio-megnetotelluric (AMT) method surveying (Abedi \& Norouzi, 2012; An \& Di, 2007; Chen et al., 2009; Van Tuyen, 2011; Manzella \& Zaja, 2006; Sampson \& Rodriguez, 2010) was selected. To obtain an obvious result and with more reliability, we have measured electrical resistivity and polarizable of the geological samples and the drilling samples for the AMT surveying data analyzing. Further studies will attempt to determine if induced polarization parameters extracted from the AMT surveying data, also can be used to determine the size and electrical resistivity of the mineralized area.

\section{Geological Setting}

The Yuele lead-zinc mining area belongs to the northern part of the lead-zinc polymetallicmetallogenic belt in the northeastern Yunnan province "Figure 1(A)". Its special geological structural position and complex structural evolution history, has decisively influenced on the lead-zinc mineralization. The regional outcropped is made up of a suite of Paleozoic volcanic rocks, terrigenousclastic rocks, and carbonate rock. The continuous outcrops include the Ordovician, Silurian and Devonian strata in this region, the total thickness is more than 3000 meters.

And the copper, lead and zinc ore-bodies almost exist in the carbonate rocks in different strata "Table 1, Figure 1(B)". The mainly magma rocks are the amygdaloidal and vesiculate basalt of Emei Mount Formation of Upper Permian $\left(\mathrm{P}_{2} \beta\right)$, erupted in Late Hercynian and widely distributed in the regional area of Yangtze platform in southwestern China. The influence of magma in this formation on the lead-zinc mineralization surrounding the Yangtze platform, has many different disputes.

In NE Yunnan region there are some main faults, including near SN trending Xiaojiang fault, NE trending Qiaojia-Lianfeng fault, NW trending Kangding-Daguan-Shuicheng fault, and SN trending Zhaotong-Qujing burial fault, and many developed secondary faults. There lay some dome structures near SN trending MohanQinglin belong to the northeastern section of Sayu River fold syncline eastern wing of Zhenxiong-Zhaotong fault, the main part position is secondary extensive wide and gently monoclinal structure of anticline eastern wing. The $F_{1}$ and $F_{2}$ thrust faults across anticline core is located in near SN trending, alternate NE NEE trending secondary folds, NW-NNW and NE-NNE trending faults and interlayer fracture zone, and formed the structure pattern with grid shape "Figure 1(B)".

The uncovering projects determined three types of copper, lead and zinc deposits in this mining area, the upper part are vein-type $\mathrm{Pb}-\mathrm{Zn}(-\mathrm{Ag})$ ore-bodies and stratiform-type $\mathrm{Cu}-\mathrm{Pb}$ - $\mathrm{Ag}$ ore-bodies, the under part is stratiform-type $\mathrm{Pb}-\mathrm{Zn}$ (-Ag) ore-bodies. The main ore-bearing strata are limestone, carbonaceous debris argillaceous limestone, dolomitic limestone, calcite dolomite, and quartz sandstone in Ordovician and Silurian formation. Three types of ore-bodies exist together with similar geological features and obvious forming origin relationship. The 

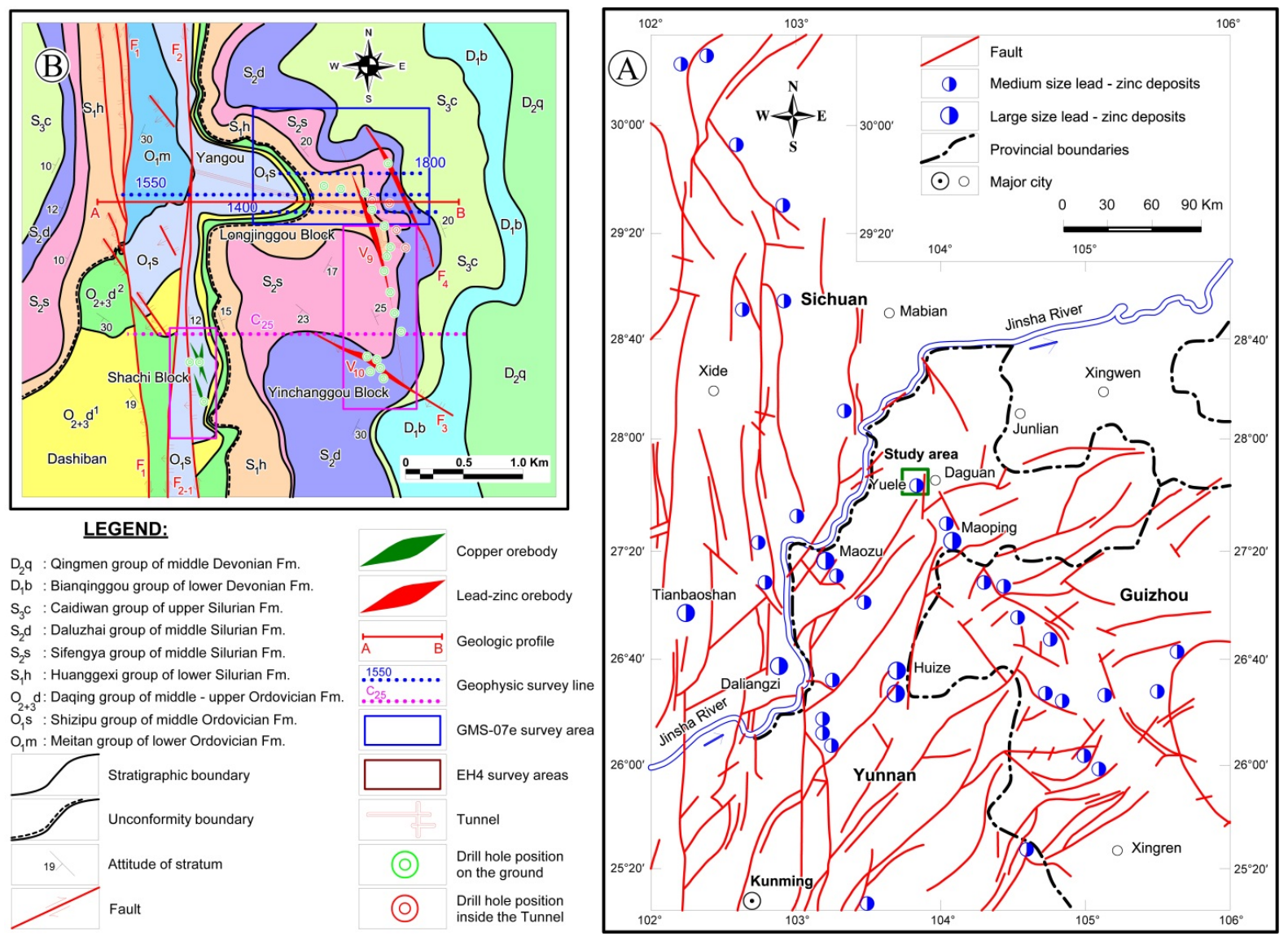

Figure 1. The regional and ore field geological map of Yuele lead-zinc deposit. A show the distribution of lead-zinc deposits in Sichuan-Yunnan-Guizhou border area (modified from Liu and Lin, 1999). B shows the structure outline map in Yuele lead-zinc deposit. The low Panel shows the AB geological profile.

known ore-bodies (ore mineralization bodies) are produced from in flanking plume-like fractures and steep dipping tension-torsional faults and fracture zones that is near $\mathrm{SN}$ trending and eastern plate of the $\mathrm{F}_{2}$ fault. Order of faults and ore-bodies (mineralization bodies) can be arranged as follows, the $F_{2}, F_{3}, F_{4}$ and $F_{5}$ fault produced the $\mathrm{V}_{16}(\mathrm{Cu}-\mathrm{Pb}), \mathrm{V}_{10}(\mathrm{~Pb}-\mathrm{Zn}), \mathrm{V}_{8}(\mathrm{~Pb}-\mathrm{Zn})$ and $\mathrm{V}_{9}(\mathrm{~Pb}-\mathrm{Zn})$ ore-body (mineralization body).

The forms of ore minerals are simple. The main ore minerals have galena, sphalerite, pyrite and little chalcocite, chalcopyrite. The main gangue minerals have calcite, dolomite, quartz, barite, gypsum and little fluorite. The main ores have layer, stratiform, vein, stockwork, and massive structure. Concretization is automorphic, hypautomorphic, xenomorphic, metasomatic corrosion and metasomatic relict. In this mining area, the copper, lead and zinc ore-bodies are vein-type deposit, filled on epigenetic by low temperature hydrothermal, controlled by salt tectonics related to thrust fold. Salt-related structures are spatial-temporal relationship well with copper, lead and zinc polymetallic mineralization.

\section{Method and Geophysical Data Analysis}

\subsection{Field Work}

Two geophysical surveys had been done in the Yuele mining area, and two different geophysical instruments of EH4 instrument and GMS-07e instrument are used. Both of the instruments are audio-magnetotelluric sounding "Figure 1(B)".

The EH4 instrument has been surveyed in April 2011, sum of survey line are 13 lines, sum of survey station are 226 stations, sum of survey line's length are $7580 \mathrm{~m}$. The distance between two adjacent survey stations is $30 \mathrm{~m}$. And the GMS-07e instrument has been surveyed in December 2012, sum of survey line are 5 lines, sum of survey station are 224 stations, sum of survey line's length are $7200 \mathrm{~m}$. The distance between two adjacent sur- 
Table 1. The stratum characteristics profiles in Yuele lead-zinc ore field.

\begin{tabular}{|c|c|c|c|c|c|c|c|}
\hline \multicolumn{2}{|c|}{ Age } & \multirow{2}{*}{$\begin{array}{l}\text { Formation } \\
\text { Qingmen }\end{array}$} & \multirow{2}{*}{$\begin{array}{l}\text { Code } \\
\mathrm{D}_{2} \mathrm{q}\end{array}$} & \multirow{2}{*}{ Lithology } & \multirow[t]{2}{*}{ Ore bodies } & \multirow{2}{*}{\begin{tabular}{l}
\multicolumn{1}{c}{ Stratum features } \\
Argillaceous siltstone, argillite \\
bedded with marls
\end{tabular}} & \multirow{2}{*}{\begin{tabular}{|c|}
$\begin{array}{c}\text { Thickness } \\
\text { (meter) }\end{array}$ \\
$38-72$ \\
\end{tabular}} \\
\hline \multirow{13}{*}{\multicolumn{2}{|c|}{ 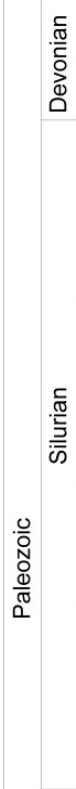 }} & & & & & & \\
\hline & & Bianqinggou & $\mathrm{D}_{1} \mathrm{~b}$ & $\begin{array}{l}=L-L-4 \\
L-L-L \\
L-L-1\end{array}$ & & Calcilutite & $0-120$ \\
\hline & & \multirow{3}{*}{ Caidiwan } & $\mathrm{S}_{3} \mathrm{C}^{3}$ & 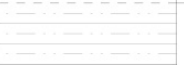 & & $\begin{array}{l}\text { Argillite bedded fine grain } \\
\text { quartz sandstone }\end{array}$ & \multirow{3}{*}{100} \\
\hline & & & $\mathrm{S}_{3} \mathrm{C}^{2}$ & $\begin{array}{l}1-\ldots-\ldots] \\
1-1 \ldots-1 \\
-1-1-1-\end{array}$ & & $\begin{array}{l}\text { Argillaceous limestone, silty } \\
\text { argillite }\end{array}$ & \\
\hline & & & $\mathrm{S}_{3} \mathrm{C}^{1}$ & & & $\begin{array}{l}\text { Carbonaceous graptolite } \\
\text { shale }\end{array}$ & \\
\hline & & \multirow{3}{*}{ Daluzhai } & $\mathrm{S}_{2} \mathrm{~d}^{3}$ & 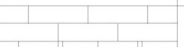 & \multirow{3}{*}{ (1) $\mathrm{Pb} \mathrm{Zn} \mathrm{Ag}$} & Fine grained limestone & \multirow{3}{*}{91.6} \\
\hline & & & $\mathrm{S}_{2} \mathrm{~d}^{2}$ & 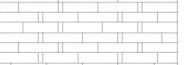 & & $\begin{array}{l}\text { Calcite dolomite with shale } \\
\text { strip limestone }\end{array}$ & \\
\hline & & & $\mathrm{S}_{2} \mathrm{~d}^{1}$ & 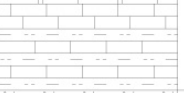 & & $\begin{array}{l}\text { Carbonaceous silty mudstone } \\
\text { interblending with bioclastic } \\
\text { limestone }\end{array}$ & \\
\hline & & \multirow{2}{*}{ Sifengya } & $\mathrm{S}_{2} \mathrm{~s}^{2}$ & 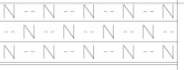 & & $\begin{array}{l}\text { Fine and medium grained } \\
\text { feldspar quartz sandstone }\end{array}$ & \multirow{2}{*}{176.3} \\
\hline & & & $\mathrm{S}_{2} \mathrm{~S}^{1}$ & & & $\begin{array}{l}\text { Carbonaceous silty mudstone } \\
\text { with siltstone }\end{array}$ & \\
\hline & & \multirow{3}{*}{ Huanggexi } & $\mathrm{S}_{1} \mathrm{~h}^{3}$ & 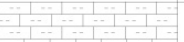 & & Carbon calcarenite & \multirow{3}{*}{$>300$} \\
\hline & & & $\mathrm{S}_{1} \mathrm{~h} 2$ & $\begin{array}{lll}0 \\
0\end{array}$ & $\mathrm{~Pb} \mathrm{Zn} \mathrm{Ag}$ & $\begin{array}{l}\text { Fine grained limestone } \\
\text { bedded with dolomitic } \\
\text { limestone }\end{array}$ & \\
\hline & & & $\mathrm{S}_{1} \mathrm{~h} 1$ & 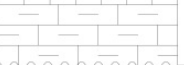 & & $\begin{array}{l}\text { Carbonaceous argillaceous } \\
\text { limestone }\end{array}$ & \\
\hline & \multirow{6}{*}{$\frac{c}{\frac{\pi}{0}}$} & \multirow{2}{*}{ Daqing } & $\mathrm{O}_{2+3} \mathrm{~d}^{2}$ & $-1-\cdots-\cdots$ & Gypsum & $\begin{array}{l}\text { Silty mudstone and } \\
\text { gypsum-bearing siltstone }\end{array}$ & \multirow{2}{*}{118.8} \\
\hline & & & $\mathrm{O}_{2+3} \mathrm{~d}^{1}$ & 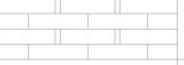 & (5) & $\begin{array}{l}\text { Dolomite bedded with } \\
\text { limestone }\end{array}$ & \\
\hline & & \multirow{3}{*}{ Shizipu } & $\mathrm{O}_{1} \mathrm{~s}^{3}$ & 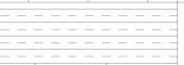 & \multirow{3}{*}{ (1) Pb Zn Ag } & Mudstone bedded with marls & \multirow{3}{*}{$>250$} \\
\hline & & & $\mathrm{O}_{1} \mathrm{~s}_{2}$ & $\Delta \infty$ & & Fine grained calcite dolomite & \\
\hline & & & $\mathrm{O}_{1} \mathrm{~s} 1$ & $-1-1-1]$ & & Limestone with argillite & \\
\hline & & Meitan & $\mathrm{O}_{1} \mathrm{~m}$ & $\cdots \equiv \ldots \ldots \bar{\ldots}$ & & Argillite and silty shale & 171.1 \\
\hline
\end{tabular}

vey stations is $30 \mathrm{~m}$.

\subsection{AMT Method}

\subsubsection{Basic Equations}

Basis of the magnetotelluric theory are Maxwell's equations, reduced for quasi stationary fields in the frequency domain, as the basis of magnetotelluric theory:

$$
\begin{gathered}
\nabla \times B=\mu_{r} \mu_{0} \sigma E \\
\nabla \times \mathrm{E}=-\mathrm{i} \omega \mathrm{B} \\
\nabla \cdot \mathrm{B}=0 \\
\nabla \cdot \epsilon \epsilon_{0} \mathrm{E}=\rho_{\mathrm{el}}=0
\end{gathered}
$$

with $\mathrm{E}(\mathrm{t})=\mathrm{E}_{0} \mathrm{e}^{\mathrm{i} \omega \mathrm{t}}$ (positive exponent, harmonic wave).

Electric fields are produced by electric charges and time-varying magnetic fields; magnetic fields are produced by currents and time-varying electric fields. Further basic assumptions are that the material is isotropic and normal polarisable, and that no extrinsic electric currents are flowing (no unknown sources). The response function of the rocks is not frequency dependent nor influenced by pressure or temperature.

This leads to the Helmholtz equation in the frequency domain

$$
\Delta \mathrm{F}=\mathrm{i} \omega \mu \sigma \mathrm{F} \text { with } \mathrm{F}=\mathrm{E}, \mathrm{B}
$$

then the transformation in the wave number domain follows 


$$
F(z, k, \omega)=\int F(z, R, \omega) e^{-i k R} d R
$$

with $\mathrm{dR}=\mathrm{dxdy}$ and $\mathrm{dk}=\mathrm{dk}_{\mathrm{x}} \mathrm{dk}_{\mathrm{y}}$; the Laplace operator becomes a factor

$$
\begin{gathered}
\Delta=\frac{\mathrm{d}^{2}}{\mathrm{dz}^{2}}-\mathrm{k}^{2} \\
\Delta F=\left(i \omega \mu \sigma+k^{2}\right) F
\end{gathered}
$$

we obtain the complex vertical wave number and the complex skin depth

$$
C^{-1}=K=\sqrt{i \omega \mu \sigma+k^{2}}
$$

and with $k \approx 0$ (quasi homogeneous source field) the real skin depth.

$$
p=\sqrt{\frac{2}{\omega \mu \sigma}}
$$

Simply spoken, the source of the magnetotelluric fields is in the magnetosphere and ionosphere, separated by the non conductive atmosphere. The field is varying slowly, so that wave terms can be neglected and the diffusion equations are valid. The inducing fields are plane waves and do not vary in a range of 500 to $1000 \mathrm{~km}$ : differences in transfer functions are caused by fields from the subsurface and not by different inducing fields from above. The conductivity of the rocks is not frequency dependent: a change of conductivity at a certain frequency is caused by different conductivities in different rocks.

The limitation is listed as follows:

- In polar and equatorial regions the field from the polar and equatorial electrojet is not plane $(k ! \approx 0)$.

- At high frequencies (above $20 \mathrm{kHz}$ ) over resistive material (e.g. granite) wave terms become more and more important.

- Bay variations might not be correlated up to 500 or $1000 \mathrm{~km}$.

- At very high induction depths where the skin depths reach the dimension of $\mathrm{k}$.

- The plane and far field assumption can be invalid during AMT recordings if thunderstorms are nearby.

- Controlled source methods have to be evaluated by other means.

\subsubsection{Impedance Function}

The impedance function describes the relation between the electric and magnetic field is:

$$
\left(\begin{array}{c}
E_{x} \\
E_{y}
\end{array}\right)=\left(\begin{array}{ll}
Z_{x x} & Z_{x y} \\
Z_{y x} & Z_{y y}
\end{array}\right)\left(\begin{array}{l}
B_{x} \\
B_{y}
\end{array}\right)
$$

where, in the $1 \mathrm{D}$ case (homogeneous half space or plain, layered earth) $Z_{x y}=-Z_{y x}$.

The apparent resistivity is defined as:

$$
\rho_{a x y}=\frac{\mu_{0}}{\omega}\left|Z_{x y}\right|^{2}=\frac{\mu_{0}}{\omega}\left|\frac{E_{x}}{B_{y}}\right|^{2}=\omega \mu_{0}\left|C_{x y}\right|^{2} \approx \omega \mu_{0} \frac{p^{2}}{2}
$$

it can be necessary to multiply $\mathrm{Z}$ with 1000 before taking the absolute value in case the electrical field was in $\mathrm{mV} / \mathrm{km}$.

with its error:

$$
\Delta \rho_{\text {a xy }}=2 \rho_{\text {a xy }} \frac{\Delta Z_{x y}}{\left|Z_{\text {xy }}\right|}=\frac{2 \mu_{0}}{\omega}\left|Z_{\text {xy }}\right| \Delta Z_{\text {xy }}
$$

and the phase:

$$
\varphi_{\mathrm{xy}}=\arg \left(\mathrm{Z}_{\mathrm{xy}}\right)=\arctan \left(\frac{\operatorname{Im}\left(\mathrm{Z}_{\mathrm{xy}}\right)}{\operatorname{Re}\left(\mathrm{Z}_{\mathrm{xy}}\right)}\right)
$$

with its error: 


$$
\Delta \varphi_{\mathrm{xy}}=\frac{\Delta \mathrm{Z}_{\mathrm{xy}}}{\left|\mathrm{Z}_{\mathrm{xy}}\right|}
$$

Hence that, the phase $\varphi_{x y}$ should be in the range of $0-90^{\circ}$ and $\varphi_{y x}$ in the range of $-90^{\circ}-180^{\circ}$ degrees because $\mathrm{Z}$ is complex and one has to respect the quadrant in the complex plane:

$$
\varphi=\left\{\begin{array}{c}
\arctan \left(\frac{I m}{\mathrm{Re}}\right) \text { if } R e>0 \text { and } I m \geq 0 \\
\arctan \left(\frac{\operatorname{Im}}{\mathrm{Re}}\right)+\pi \text { if } R e<0 \text { and } \operatorname{Im} \geq 0 \\
\arctan \left(\frac{\operatorname{Im}}{\mathrm{Re}}\right)-\pi \text { if } R e<0 \text { and } \text { Im }<0
\end{array}\right.
$$

The error of $\mathrm{C}$ is

$$
\Delta C_{x y}=\frac{\Delta Z_{x y}}{\omega}
$$

\subsubsection{More Dimensions}

In the $1 \mathrm{D}$ case we had $Z_{x y}=-Z_{y x}$ and $Z_{x x}=Z_{y y}=0$. In the 2 and more dimensional case all elements of the impedance function are containing values and $Z_{x y} \neq Z_{y x}$.

\subsubsection{Swift's Angle and Rotation}

The function can be rotated with the matrix

$$
D=\left(\begin{array}{cc}
\cos \cos \alpha & \sin \sin \alpha \\
-\sin \sin \alpha & \cos \cos \alpha
\end{array}\right)
$$

(hence that in the MT coordinate system $x$ is North, $y$ is East and $z$ is positive downwards).

The function can be rotated using Swift's formula to minimize $\left|Z_{x x}\right|^{2}$ and $\left|Z_{y y}\right|^{2}$

with the error

$$
\alpha=\frac{1}{4} \arctan \frac{2 \operatorname{Re}\left(Z_{x y}+Z_{y x}\right) \overline{\left(Z_{x x}-Z_{y y}\right)}}{\left(\left|Z_{x x}-Z_{y y}\right|^{2}-\left|Z_{x y}-Z_{y x}\right|^{2}\right)}
$$

$$
\Delta \alpha=\frac{1}{4} \sqrt{\frac{\left|Z_{x x}-Z_{y y}\right|^{2}\left(\Delta Z_{x y}+\Delta Z_{y x}\right)^{2}+\left|Z_{x y}-Z_{y x}\right|^{2}\left(\Delta Z_{x x}+\Delta Z_{y y}\right)^{2}}{\left(Z_{x y}|-| Z_{x y}-Z_{y x} \mid\right)^{2}\left(2 \operatorname{Re}\left(\left(Z_{x x}-Z_{y y}\right)\left(Z_{x y}+Z_{y x}\right)\right)\right)}}
$$

The Swift angle has a periodicy of $\pi / 4$ because of the arctan function. If you test for the second derivative

$$
2 \operatorname{Re}\left(Z_{x y}+Z_{y x}\right) \overline{\left(Z_{x x}-Z_{y y}\right)} \sin \sin 4 \alpha+\left(\left|Z_{x x}-Z_{y y}\right|^{2}-\left|Z_{x y}+Z_{y x}\right|^{2}\right) \cos \cos 4 \alpha>0
$$

You should get the correct angle, where by convention $Z_{x y} \leq Z_{y x}$. The Swift's angle can be different for every frequency if no 2D structure is dominant. The angle is undefined and unstable if the anisotropy is low. When you evaluate a complete MT profile it can be a good idea to set an anisotropy limit; if the anisotropy after rotation is below that value you skip the rotation and let the angle be 0 . In the cross section showing your Swift's angle it is then simple to find a dominating angle.

\subsubsection{Anisotropy and Skewness}

The anisotropy is defined as

$$
A=\frac{\left|Z_{y x}\right|}{\left|Z_{x y}\right|}
$$


with the error

$$
\Delta A=A \sqrt{\frac{\Delta Z_{x y}^{2}}{\left|Z_{x y}\right|^{2}}+\frac{\Delta Z_{y x}^{2}}{\left|Z_{y x}\right|^{2}}}
$$

as mentioned above, the anisotropy is dependent on the rotation angle of the impedance tensor.

The skewness can be a parameter of the dimensionality of the impedance tensor; the skewness is defined as

$$
S=\left|\frac{\left|Z_{x x}+Z_{y y}\right|}{\left|Z_{x y}-Z_{y x}\right|}\right|
$$

with the error

$$
\Delta S=\sqrt{\frac{\left|Z_{x x}-\Delta Z_{x x}\right|^{2}\left|Z_{y y}-\Delta Z_{y y}\right|^{2}}{\left|Z_{x x}-Z_{y y}\right|^{4}}+\frac{\left|Z_{x y}-\Delta Z_{x y}\right|^{2}\left|Z_{y x}-\Delta Z_{y x}\right|^{2}}{\left|Z_{x y}-Z_{y x}\right|^{4}}}
$$

The skewness should be $<0.3$ to interpret the structure as 2D. However, even on 3D structures you find positions with a skewness which is almost zero.

\subsubsection{Induction Arrows, Tipper}

Induction arrows describe the transfer function between the horizontal components of the magnetic field and the vertical component

$$
B_{z}=\left(\begin{array}{ll}
z_{H} & z_{D}
\end{array}\right)\left(\begin{array}{l}
B_{x} \\
B_{y}
\end{array}\right)
$$

It is useful to draw an arrow with the length

$$
Z_{\text {real length }}=\left|\operatorname{Re}\left(Z_{H}\right)\right|+\left|\operatorname{Re}\left(Z_{D}\right)\right|
$$

and direction (from North over East).

$$
Z_{\text {realang }}=\arctan \frac{\operatorname{Re}\left(Z_{D}\right)}{\operatorname{Re}\left(Z_{H}\right)}
$$

The arrowhead of the real induction arrow is pointing away from a conductive structure

The errors of length and angles are

$$
\begin{gathered}
\Delta Z_{\text {real length }}=\sqrt{\left(\frac{2 \operatorname{Re}\left(Z_{H}\right) \Delta Z_{H}}{\sqrt{\left(\operatorname{Re}\left(Z_{H}\right)^{2}+\operatorname{Re}\left(Z_{D}\right)^{2}\right)}}\right)^{2}+\left(\frac{2 \operatorname{Re}\left(Z_{D}\right) \Delta Z_{D}}{\sqrt{\left(\operatorname{Re}\left(Z_{H}\right)^{2}+\operatorname{Re}\left(Z_{D}\right)^{2}\right)}}\right)^{2}} \\
\Delta Z_{\text {real ang }}=\sqrt{\left(\frac{\operatorname{Re}\left(Z_{H}\right) \Delta Z_{H}}{\left(\operatorname{Re}\left(Z_{H}\right)^{2}+\operatorname{Re}\left(Z_{D}\right)^{2}\right)}\right)^{2}+\left(\frac{\operatorname{Re}\left(Z_{D}\right) \Delta Z_{D}}{\left(\operatorname{Re}\left(Z_{H}\right)^{2}+\operatorname{Re}\left(Z_{D}\right)^{2}\right)}\right)^{2}}
\end{gathered}
$$

$\rho^{*}-z^{*}$

Schmucker's $\rho^{*}-z^{*}$ transformation gives a first resistivity-depth interpretation of the acquired data

$$
\rho_{x y}^{*}=\left\{\begin{array}{c}
\rho_{a x y} 2 \cos ^{2} \cos ^{2} \varphi \text { or } 2 \omega \mu_{0} \mu_{r} \operatorname{Im}\left(C_{x y}\right) \text { if } \varphi_{x y} \geq 45^{\circ} \\
\rho_{a x y} \frac{1}{2 \sin ^{2} \sin ^{2} \varphi_{x y}} \text { or } \frac{\mu_{0} \mu_{r}}{2 \omega \operatorname{Im}\left(1 / i \omega C_{x y}\right)^{2}} \text { if } \varphi_{x y}<45^{\circ}
\end{array}\right.
$$




\section{Survey station}
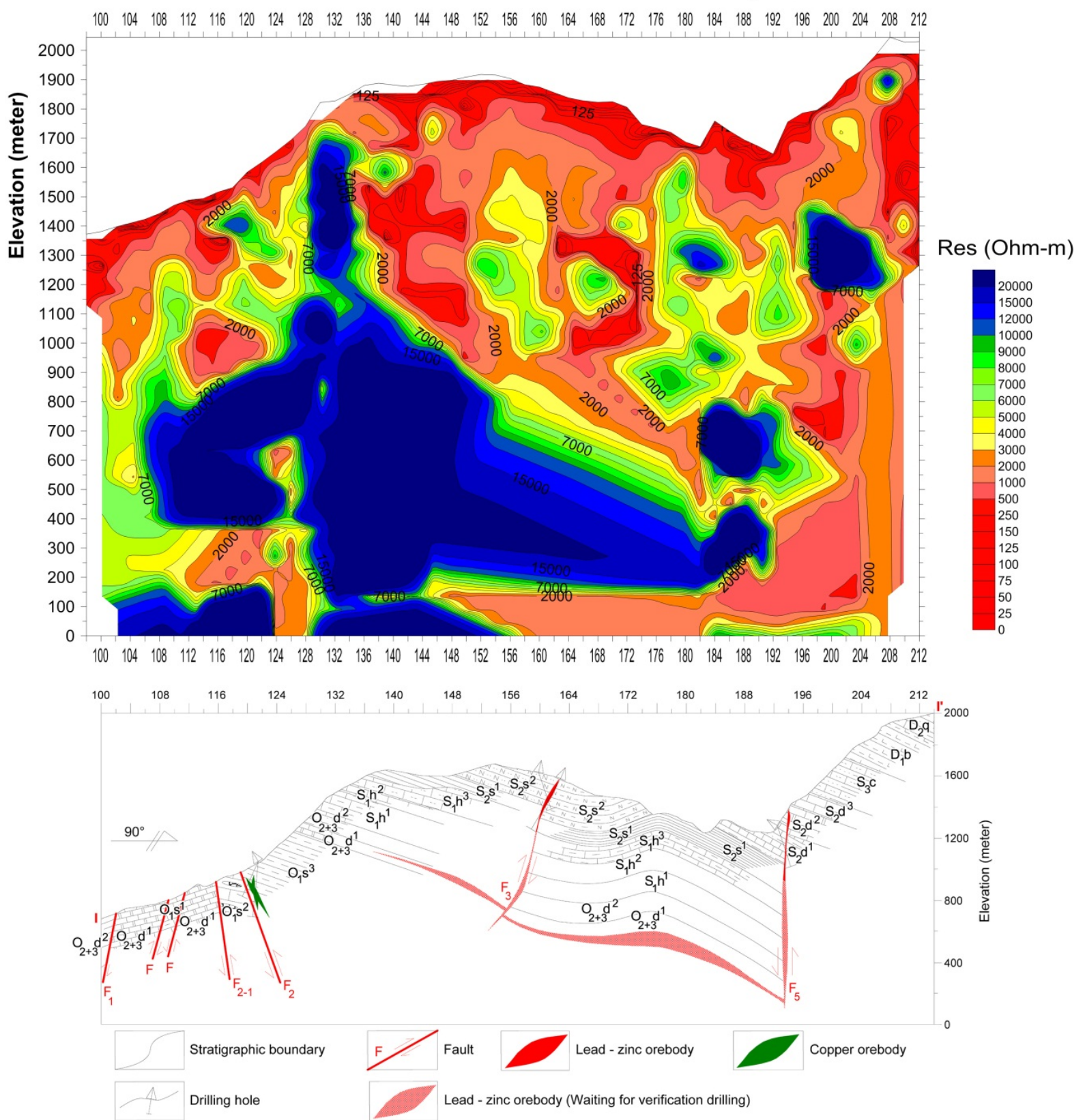

Figure 2. The electrical resistivity 2D inversion profile of line C25 and its geological interpretation, the survey line position is line C25 with dotted violet line in "Figure 1(B)".

$$
z_{x y}^{*}=\operatorname{Re}\left(Z_{x y}\right)
$$

with the errors

$$
\Delta \rho_{x y}^{*}=\left\{\begin{array}{l}
2 \rho_{x y}^{*} \frac{\Delta Z_{x y}}{\left|\operatorname{Re}\left(Z_{x y}\right)\right|} \text { if } \varphi_{x y} \geq 45^{\circ} \\
2 \rho_{x y}^{*} \frac{\Delta Z_{x y}}{\left|\operatorname{Im}\left(Z_{x y}\right)\right|} \text { if } \varphi_{x y}<45^{\circ}
\end{array}\right.
$$



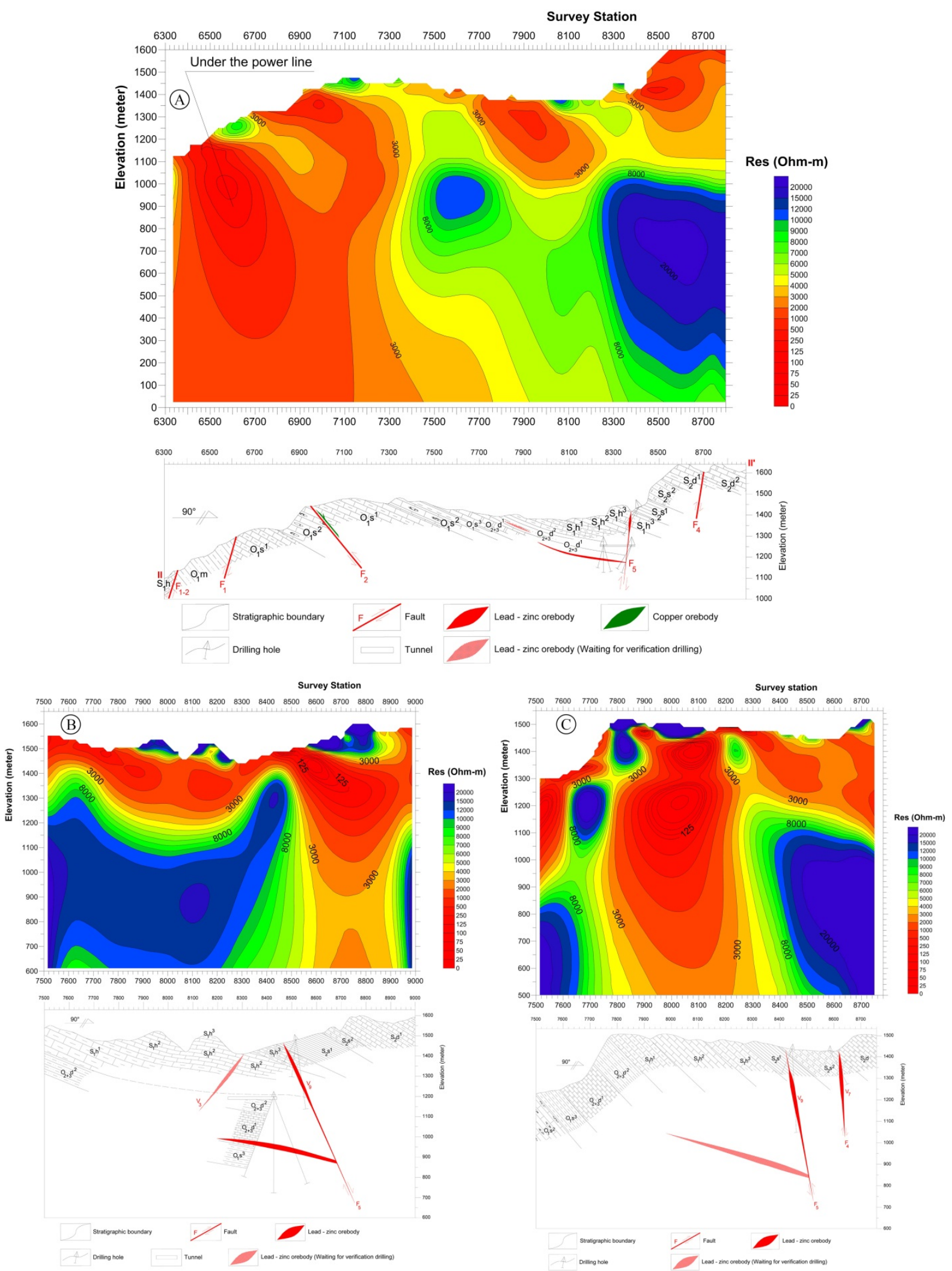

Figure 3. The electrical resistivity 2D inversion and its geological interpretation, the survey line position is the line with dotted green line in "Figure 1(B)". a-line 1550; b-line 1400; c-line 1800. 


$$
\Delta z_{x y}^{*}=\operatorname{Re}\left(\frac{C \Delta Z_{x y}}{\operatorname{Re}\left(C_{x y}\right)}\right)
$$

\subsection{Analytical Methods}

The software used to analysis ATM surveying data is the software Mapros.

1) Using the fast Fourier transform algorithm (FFT) to obtain the corresponding spectrum for the collected data, that is the corresponding relation between the frequency and amplitude in electric field or magnetic field.

2) Using the impedance equation to obtain the corresponding relation between the Cagniard resistivity and frequency.

3) Using the software MT Pioneer to display the two-dimensional electrical resistivity inversion profile from the collected data, fitting the collected data and establishment model.

4) Colligate the one-dimensional inversion and two-dimensional inversion to obtain the inversion finally.

The collected data after passing these processes, get the resistivity inversion section of each survey line. Combined with the geological data, drilling and other data to inference and interpretation.

\section{Inference and Interpretation Results}

The analysis of 2D electrical resistivity inversion profile of the AMT method, combination of known geological data and borehole data, bring into comparisons with strata and structure of electrical resistivity inversion profile has been shown. Analysis of all the electrical resistivity inversion profiles to anomaly division of geophysical exploration and interpretation of geophysical exploration inversion profiles. Because of mine for low temperature hydrothermal vein type deposit, the ore mainly belong to epigenetic mineralization product filling, ore-body is significantly affected by the fracture zone and the ore-bearing strata combined.

According to the borehole data have known obtainable orebody output area mostly associated with carbonaceous mudstone, limestone and that is corresponding to low electrical resistivity site of sounding inversion profile.

Therefore, when anomaly body divided according to the reflection of sounding electrical resistivity profile, combined with geological data and borehole data to inference and after that comprehensive analysis was carried out to determine "Figure 2, Figure 3".

\section{Conclusions}

1) The interpretation results of the AMT method have identified the location of geological structure, deformation forms, and their spatial occurrence and depth variation.

2) Comparing the interpretation results of the AMT method with the known borehole data, it is shown that the location of medium electrical resistivity anomalies is the location of lead and zinc mineralization, the value of medium electrical resistivity anomalies is about $1000-3000(\Omega \cdot \mathrm{m})$.

3) Based on the interpretation results of the AMT method, combined with the geological conditions and the known borehole data, the anomalies area can be designed as the drill verification to carry out the mineral predicting.

\section{Acknowledgements}

This study is financially supported by the Doctoral Fund Projects of Education Ministry of China (20125314110006), the Natural Science Fund Project of Yunnan Province (2009CI030) and the Science and Technology Project of Yunnan Chihong Zinc and Germanium Co. Ltd. We thank Mr. Xing Li, Wei Yao, JieNiu, Yanqing Hu and other geological engineers for their help during the field work. We sincerely thank Dr. Yurong Gong and other reviewer for their comments and suggestions.

\section{References}

Abedi, M., \& Norouzi, G. H. (2012). Integration of Various Geophysical Data with Geological and Geochemical Data to Determine Additional Drilling for Copper Exploration. Journal of Applied Geophysics, 83, 35- 45. http://dx.doi.org/10.1016/j.jappgeo.2012.05.003 
An, Z. G., \& Di, Q. Y. (2007). Application of CSAMT Method for Exploring Coal Mine in Fujian Province, Southeastern China.Geophysics, 3, 430- 443.

Bostick Jr., F. X. (1977). A Simple and Almost Exact Method of MT Analysis. Workshop on Electrical Methods in Geothermal Exploration: Salt Lake City, Utah, University of Utah, 175-177.

Cagniard, L. (1950). Procédé de prospection géophysique [Procedure of geophysical prospecting]. French Patent No. 1025683, 6 p.

Cagniard, Louis, (1953). Basic Theory of the Magnetotelluric Method of Geophysical Prospecting. Geophysics, 18, 605-635. http://dx.doi.org/10.1190/1.1437915

Chen, Y. X., Di, Q. Y., \& da Gama, C. D. (2009). Case studies of CSAMT Method Applied to Study of Complex Rock Mass Structure and Hidden Tectonic. World Academy of Science, Engineering and Technology, 32, 209-214.

Dmitriev, V. I., \& Berdichevsky, M. N. (1979). The Fundamental Model of Magnetotelluric Sounding. Proceedings of the IEEE (Institute of Electrical and Electronics Engineers), 67, 1034-1044. http://dx.doi.org/10.1109/PROC.1979.11386

Gamble, T. D., Goubau, W. M., \& Clarke, J. (1979a). Magnetotellurics with a Remote Magnetic Reference. Geophysics 44, 53-68. http://dx.doi.org/10.1190/1.1440923

Gamble, T. D., Goubau, W. M., \& Clarke, J. (1979b). Error Analysis for Remote Reference Magnetotellurics. Geophysics, 44, 959- 968. http://dx.doi.org/10.1190/1.1440988

Gubins, A., \& Strangway, D. W. (1978). Magnetic and Audio Frequency Magnetotelluric (AMT) Investigations at the Dumas and Viewfield, Saskatchewan Astroblemes [abs.]. Eos, Transactions, American Geophysical Union, 59, 1036.

Hermance, J. F., Thayer, R. E., \& Bjornsson, A. (1976). The Teiluric-Magnetotelluric Method in the Regional Assessment of Geothermal Potential. Report, 2-7.

Hoover, D. B., Frischknecht, F. C., \& Tippens, C. L. (1976). Audiomagnetotelluric Sounding as a Reconnaissance Exploration Technique in Long Valley, California.Journal of Geophysical Research, 81, 801-809. http://dx.doi.org/10.1029/JB081i005p00801

Liu, H. C., \& Lin, W. D. (1999). The Metallogenetic Rules of Lead, Zinc and Silver Deposit in Northeastern Yunnan Province. Kunming: Yunnan University Press.

Manzella, A., \& Zaja, A. (2006). Volcanic Structure of the Southern Sector of Mt. Etna after the 2001 and 2002 Eruptions Defined by Magnetotelluric Measurements. Bull. Volcanol, 69, 41-50. http://dx.doi.org/10.1007/s00445-006-0054-9

Sampson, J. A., \& Rodriguez, B. D. (2010). Audio-Magnetotelluric Survey to Characterize the Sunnyside Porphyry Copper System in the Patagonia Mountains, Arizona. Report, 3-4.

Van Tuyen, D. D. (2011).Results of Survey by Electrical Method for Investigating Groundwater Resources in Hon La Economic-Shipping Port Area, QuangBinh Province. Geophysics, 3, 549-553.

Wang, M., Fan, J. Z., Wang, Z. W., \& Ma, Y. Y. (2009).Comprehensive Prospecting Model for Lead-Zinc Deposit of Huanggang-Ganzhuermiaometallogenic Belt, Inner Mongolia.Earth Science Frontiers, 16, 318-324. http://dx.doi.org/10.1016/S1872-5791(08)60112-8

Xue, C. D., Wei, A. Y., Wang, J. R. et al. (2010). Report of Investigation Prospecting Design in Yuele Lead-Zinc Mining Area, Daguan District, Yunnan Province. Report, 9- 31

Xue, C. D., Wei, A. Y., Zhang, Y. L. et al. (2012). Report of Prospecting Study and Metallogenic Model in Yuele Lead-Zinc Mining Area, Daguan District, Yunnan Province. Report, 85- 89. 